EXCHANGE OF Mn, $\mathrm{Ca}$, Mg AND Al BETWEEN SYNTHETIC GARNET, ORTHOPYROXENE, CLINOPYROXENE AND OLIVINE

Tony A. Finnerty (Geophysical Laboratory, 2801 Upton St., N.W., Washington, D.C. 20008)

Fifteen exchange reactions among Fe-free garnet lherzolite minerals have been examined for pressure and temperature effects by experiments in the range 10 to $50 \mathrm{kbar}$ and $1100^{\circ}$ to $1400^{\circ} \mathrm{C}$. Experiments were conducted on an oxide mixture of composition ( $w t \%): \mathrm{MgO}, 34.47 ; \mathrm{Al}_{2} \mathrm{O}_{3}, 8.80 ; \mathrm{SiO}_{2}, 48.86 ; \mathrm{CaO}, 7.26$; $\mathrm{MnO}, 0.61$, that crystallizes at high pressure and temperature to roughly equal proportions of olivine, ortho- and clinopyroxene, and garnet or spinel. The powder was loaded into graphite capsules, and sealed inside Pt in the presence of a $\left(\mathrm{CO}_{2}+\mathrm{H}_{2} \mathrm{O}\right)$ - rich fluid, then run in a 1/2-inch diameter piston-cylinder high-pressure apparatus. Six grains of each mineral from each run were ana1yzed by electron microprobe. Backgrounds were analyzed at each spot for precise determination of $\mathrm{Ca}$ in olivine and $\mathrm{Mn}$ in all minerals. Standard deviations were less than $10 \%$ for $\mathrm{Ca}$ in olivine, less than $5 \%$ for a11 other oxides.

Concentrations of $\mathrm{Ca}$ in coexisting minerals at $30 \mathrm{kbar}$ (open circles) and $40 \mathrm{kbar}$ (closed circles) are presented in Fig. A. Components were calculated as $\mathrm{CaMgSi}_{2} \mathrm{O}_{6}$ (Di), $\mathrm{Ca}_{3} \mathrm{Al}_{2} \mathrm{Si}_{3} \mathrm{O}_{12}(\mathrm{Gr})$, and $\mathrm{Ca}_{2} \mathrm{SiO}_{4}$ (La). A1 in pyroxene was combined with $\mathrm{Mg}$ as $\mathrm{MgAl}_{2} \mathrm{SiO}_{6}$ (Mgts). Pyroxene compositions from $30 \mathrm{kbar}$ runs agree with the $20 \mathrm{kbar}$ data of Lindsley and Dixon (1976) in Fig. A (bars represent their reversal brackets) within analytical uncertainty, suggesting attainment of equilibrium in these runs. The natural logarithms of the concentration ratios for several equilibria calculated as, for example, $\mathrm{K}=$ $\left(\mathrm{X}_{\mathrm{Gr}} / \mathrm{X}_{\mathrm{Py}}\right)^{1 / 3}\left(\mathrm{X}_{\mathrm{En}} / \mathrm{X}_{\mathrm{Di}}\right)$ for garnet-pyroxene $\mathrm{Ca}-\mathrm{Mg}$ exchange, are plotted against inverse temperature in Fig. $B$ through $\mathrm{E}$ (numbers beside data points refer to pressure in $\mathrm{kbar}$ ).

To account for nonideality in $\mathrm{Ca}-\mathrm{Mg}$ solid solutions, exchange data were fit by least squares techniques to equations of the form:

$$
-R T \text { ln } \mathrm{K}=\Delta \overline{\mathrm{H}}^{\circ}-\mathrm{T} \Delta \overline{\mathrm{S}}^{\circ}+\mathrm{P} \Delta \overline{\mathrm{V}}^{\circ}+\sum_{\mathrm{q}} \nu_{\mathrm{q}}\left(\sum_{i \neq q} \mathrm{X}_{i} \mathrm{~W}_{i q}-\sum_{j=1}^{n-1} \sum_{k=j+1}^{n} \mathrm{X}_{j} \mathrm{X}_{k} \mathrm{~W}_{j k}\right)
$$

$\left(\Delta \overline{\mathrm{H}}^{\circ}, \Delta \overline{\mathrm{S}}^{\circ}\right.$ and $\Delta \overline{\mathrm{V}}^{\circ}$ are changes in molar enthalpy, entropy and volume, respectively, for exchange of one cation, $q, i, j, k$, and $n$ are indices of components, the $\nu^{\prime} s$ are stoichiometric coefficients in the exchange reaction, the $X^{\prime} s$ are mole fractions, and the $W^{\prime} s$ are Margules parameters for symmetric regular solutions). The fits for $\mathrm{Ca}-\mathrm{Mg}$ and $\mathrm{Al}$ exchange were constrained by values (kcal $\mathrm{gfw}^{-1}$ ) of $\mathrm{Ca}-\mathrm{Mg}$ Margules parameters of 9.6 (garnet, 12 oxygens), 53.3 (olivine, 4 oxygens), and 5.9 and 25.5 (clino- and orthopyroxene, respectively, 6 oxygens), obtained by fitting data of Newton, et a1. (1977), Warner and Luth (1973) and Lindsley and Dixon (1976), respectively, to binary symmetric regular solution models similar to Eqn. 1. Fits to data for exchange of $\mathrm{Mn}$ and $\mathrm{Mg}$ were unconstrained and, because of low Mn concentrations, an ideal solution mode1 (al1 W's in Eqn. 1 set equal_to zero) was assumed. Results are listed in the table $\left(\Delta \overline{\mathrm{H}}^{\circ}\right.$ in $\mathrm{kcal} \mathrm{gfw}^{-1}, \Delta \overline{\mathrm{S}}^{\circ}$ in ${ }^{\circ} \mathrm{K}$ cal $\mathrm{gfw}^{-1}, \Delta \overline{\mathrm{V}}^{\circ}$ in $\mathrm{cm}^{3} \mathrm{gfw}^{-1}, 1 \sigma$ standard deviations in brackets).

Exchange reactions for $\mathrm{Ca}$ and $\mathrm{Mg}$ between garnet and orthopyroxene, between garnet and clinopyroxene, and between clinopyroxene and olivine, and for $\mathrm{Mn}$ and $\mathrm{Mg}$ between clino- and orthopyroxene and between clinopyroxene and olivine, are as temperature sensitive as the diopside-enstatite equilibrium. These may be useful as geothermometers.

The effect of pressure on the exchange equilibria is nearly as large for 
A1 in clinopyroxene coexisting with garnet as is the case for orthopyroxene. The Mn-Mg equilibria display pressure effects up to $15 \%$ as strong as for A1 in pyroxenes. Simultaneous_solution for pressure and temperature using two of these equilibria whose $\Delta \vec{V}^{\circ}$ 's differ in sign may be useful as alternative barometers, about $30 \%$ as sensitive as $\mathrm{A} 1$ in pyroxenes.

The apparent effects of pressure on $\mathrm{Ca}-\mathrm{Mg}$ equilibria are strongly dependent upon A1 content of the pyroxenes. For example, a fit to the data of Lindsley and Dixon (1976) for Al-free diopside-enstatite yielded a value of $\Delta \overline{\mathrm{V}}^{\circ}=$ $-0.43 \pm 0.46 \mathrm{~cm}^{3} \mathrm{gfw}^{-1}$. More experiments are required to calibrate this effect.

$\bar{i}$ content of orthopyroxene coexisting with clinopyroxene in garnet lherzolite nodules used to construct the Lesotho geotherm of Boyd (1973) is lower than expected from experiments. Temperature estimates from Ca-Mg equilibria involving orthopyroxene are $100^{\circ}-300^{\circ} \mathrm{C}$ lower than those of Boyd (1973). Strong preference of $\mathrm{Fe}$ for ortho- over clinopyroxene is probably responsible for this discrepancy. Simultaneous solution of equations for $\mathrm{Mn}-\mathrm{Mg}$ exchange between garnet and olivine and between ortho- and clinopyroxene yields temperature estimates whose means are $60^{\circ} \mathrm{C}$ lower, and pressure estimates that average 1.9 $\mathrm{kbar}$ lower (sheared nodules) and $10.5 \mathrm{kbar}$ higher (granular nodules) than the " $\mathrm{Al}_{2} \mathrm{O}_{3}-\mathrm{Na}_{2} \mathrm{O}$ " estimates of Boyd (1973), owing most likely to the effect of $\mathrm{Cr}$ solution in garnet and clinopyroxene. Application of these exchange data to thermobarometry must await calibration of the effects of other components.

The concentration of $\mathrm{CaO}$ in olivine coexisting with ortho- and clinopyroxene decreases by about 0.002 wt $\%$ per kbar at fixed temperature, and may be useful as an empirical geobarometer with resolution of about $\pm 3 \mathrm{kbar}$. Pressures of equilibration estimated in this way for 14 garnet therzolite nodules from the Lesotho geotherm (temperatures estimated from diopside compositions) agreed with the "Al ${ }_{2} \mathrm{O}_{3}-\mathrm{Na}_{2} \mathrm{O}$ " estimates of Boyd (1973) to within $5 \mathrm{kbar}$.

\section{r References Cited}

Boyd, F.R., 1973, Geochim. Cosmochim. Acta, 37: 2533-2546.

Lindsley, D.H., and S.A. Dixon, 1976, Am. J. Sci., 276: 1235-1301.

Newton, R.C., T.V. Charlu, and O.J. Kleppa, 1977, Geochim. Cosmochim. Acta, 41: $369-377$.

Warner, R.D., and W.C. Luth, 1973, Am. Minera1., 58: 998-1008.

\begin{tabular}{lcrrr} 
& \multicolumn{1}{c}{$\Delta \overline{\mathrm{H}}^{\circ}$} & \multicolumn{1}{c}{$\Delta \overline{\mathrm{S}}^{\circ}$} & \multicolumn{1}{c}{$\Delta \overline{\mathrm{V}}^{\circ}$} & $\sigma$ (fit) \\
\hline Gar/Cpx Ca-Mg & $3.37(0.24)$ & $0.82(0.14)$ & $-1.36(0.12)$ & $4.22 \%$ \\
Gar/Opx Ca-Mg & $10.02(0.76)$ & $5.72(0.46)$ & $2.24(0.34)$ & $1.20 \%$ \\
Gar/O1v Ca-Mg & $19.00(0.30)$ & $1.22(0.18)$ & $-0.74(0.15)$ & $0.34 \%$ \\
Cpx/Opx Ca-Mg & $15.66(0.57)$ & $4.91(0.34)$ & $3.59(0.29)$ & $0.75 \%$ \\
Cpx/O1v Ca-Mg & $15.64(0.45)$ & $0.40(0.28)$ & $0.61(0.23)$ & $0.56 \%$ \\
Opx/O1v Ca-Mg & $-0.02(0.96)$ & $-4.50(0.58)$ & $-2.98(0.49)$ & $4.14 \%$ \\
Gar/Cpx A1 & $10.0(1.6)$ & $1.90(0.99)$ & $5.28(0.83)$ & $2.76 \%$ \\
Gar/Opx A1 & $1.95(0.90)$ & $-2.01(0.55)$ & $5.90(0.46)$ & $1.79 \%$ \\
Cpx/Opx A1 & $-12.8(1.1)$ & $-4.29(0.67)$ & $1.26(0.56)$ & $3.92 \%$ \\
Gar/Cpx Mn-Mg & $4.09(0.22)$ & $2.75(0.14)$ & $-0.93(0.11)$ & $5.26 \%$ \\
Gar/Opx Mn-Mg & $-3.01(0.31)$ & $0.25(0.18)$ & $-0.21(0.15)$ & $1.63 \%$ \\
Gar/O1v Mn-Mg & $-3.26(0.31)$ & $0.49(0.19)$ & $-0.40(0.16)$ & $1.36 \%$ \\
Cpx/Opx Mn-Mg & $-7.25(0.29)$ & $-2.52(0.18)$ & $0.86(0.15)$ & $2.01 \%$ \\
Cpx/O1v Mn-Mg & $-7.35(0.32)$ & $-2.25(0.20)$ & $0.54(0.17)$ & $1.76 \%$ \\
Opx/O1v Mn-Mg & $-0.09(0.42)$ & $0.27(0.25)$ & $-0.32(0.21)$ & $10.5 \%$
\end{tabular}



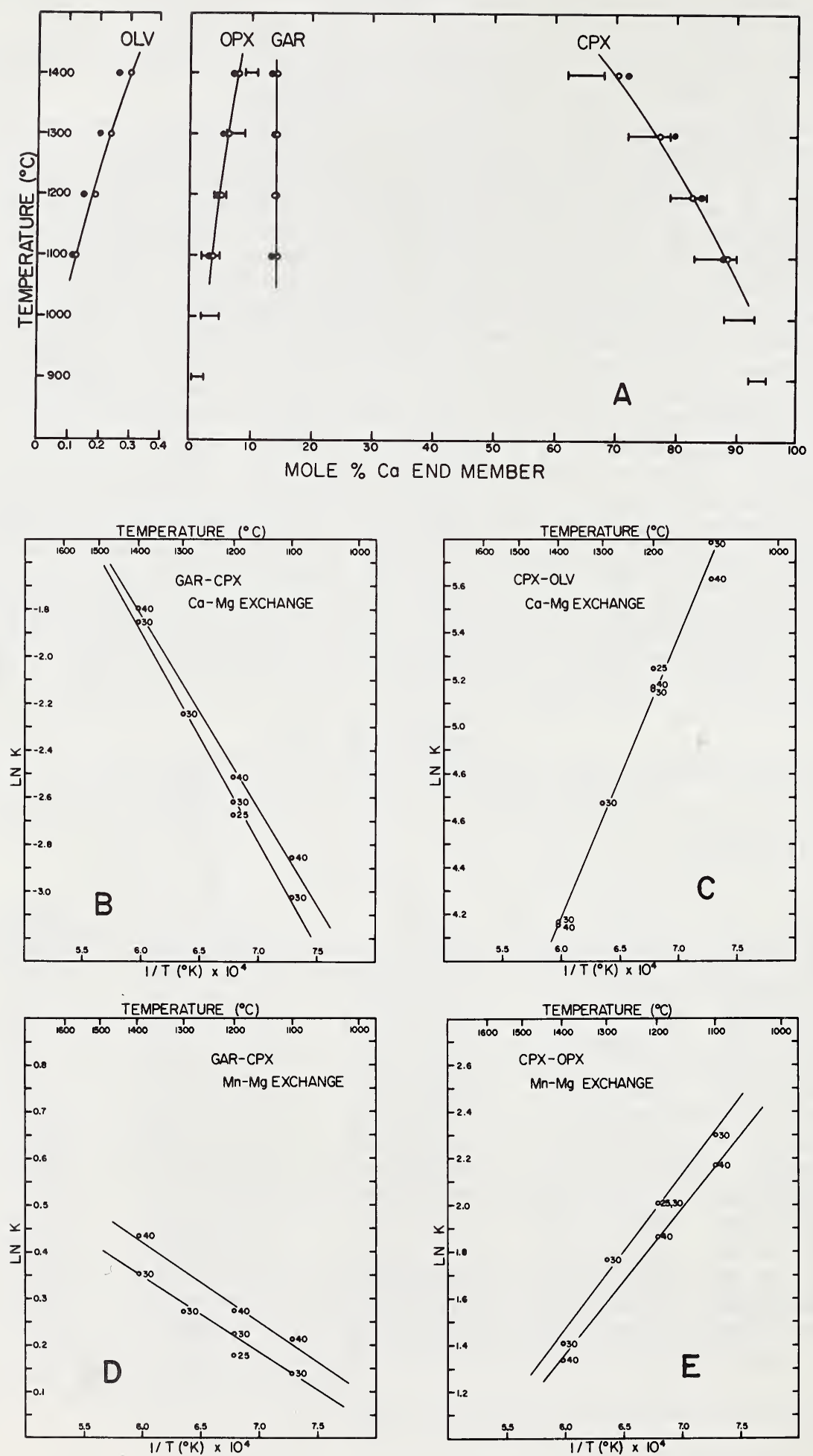